\title{
Candidate Selection, Determinant Factor for a Good Result in Cardiac Retransplantation: our Experience
}

\author{
Salterain $\mathrm{N}^{1}$, Esteban $\mathrm{A}^{1}$, Delgado $\mathrm{C}^{2}$, Bibiloni $\mathrm{I}^{2}$, Iribarren $\mathrm{MJ}^{3}$, Gavira $\mathrm{JJ}^{4}$ and Rabago $\mathrm{G}^{* 5}$ \\ ${ }^{1}$ Department of Cardiology, Clinica Universidad de Navarra, Pamplona, Spain \\ ${ }^{2}$ Department of Cardiac Surgery, Clinica Universidad de Navarra, Pamplona, Spain \\ ${ }^{3}$ Department of Anaesthesiology, Clinica Universidad de Navarra, Pamplona, Spain \\ ${ }^{4}$ Chief of Heart Failure Unit, Department of Cardiology, Clinica Universidad de Navarra, Pamplona, Spain \\ ${ }^{5}$ Vice Chairman of the Cardiology and Cardiac Surgery Department, Chief of the Heart Transplant Programme and \\ Mechanical Assist Devices, Pamplona, Spain
}

${ }^{*}$ Corresponding author: Rabago G, Vice Chairman of the Cardiology and Cardiac Surgery Department Chief of the Heart Transplant Programme and Mechanical Assist Devices, Fax: +34 948296 500, Tel: +34 948255 400, E-mail: grabago@unav.es

Citation: Salterain N, Esteban A, Delgado C, Bibiloni I, Iribarren MJ, et al. (2015) Candidate Selection, Determinant Factor for a Good Result in Cardiac Retransplantation: our Experience. J Clin Exp Res Cardiol 2(3): 303. doi: 10.15744/2394-6504.2.303

\section{Received Date: July 15, 2015 Accepted Date: November 23, 2015 Published Date: November 26, 2015}

\begin{abstract}
Introduction: Cardiac retransplantation is the standard treatment for patients with advanced graft vasculopathy. It remains controversial due to the scarcity of donors and poor results when compared with the novo transplant. Despite all the factors studied to ensure a good result, when to make a new transplant, is still a question based on the experience of each institution as their protocols. This lack of clear information in the literature complicates the proper selection of candidates. We present our experience trying to answer some of these questions.

Methods: Retrospective study of all cardiac retransplantation performed at our centre was made. Data of recipients and donors, surgical aspects and results of diagnostic tests were collected. The survival of the first and second graft was compared, as well as the survival according to the indication for retransplantation. Statistical analysis was performed using SPSS V21.

Results: 14 retransplant (5\%) and two third transplants $(0.7 \%)$ were performed. The most common cause for retransplantation was graft vascular disease $(10$ cases $(72 \%))$. Operative mortality was $14 \%$, with a survival group of $65 \pm 61$ months (median 62$)$. Second graft survival was similar to the first (median 87 months first graft vs 74 months of the second, $\mathrm{p}=0.851$ ). Poor result was achieved when indication for retrasplantation was acute rejection or primary graft failure, with a mortality of $67 \%$ (median survival for acute rejection and primary failure group 6 days vs 106 months graft vascular disease; $p=0.000$ ).

Conclusion: Cardiac retransplantation is a valid alternative in selected patients with severe dysfunction of the graft secondary to graft vasculopathy.

Keywords: Candidate selection; Cardiac Retransplantation; Graft vasculopathy

List of abbreviations: AR: Acute rejection; CRT: Cardiac retransplantation; HT: Heart Transplant; GVD: Graft vascular disease; PGF: Primary graft failure
\end{abstract}

\section{Introduction}

Despite the improvement in the survival of heart transplant (HT), survival continues to be limited by primary graft failure (PGF), acute rejection (AR) or graft vascular disease (GVD)), impacting the quality of life and good long-term outcome of these patients. The only effective treatment in this situation is the cardiac retransplantation (CRT) [1]. According to the data published in both national and international registries, up to $2-3 \%$ of transplanted patients will need a new procedure in the future [2,3].

When and to whom to make a second, third or new transplant it was, has been, is and will be a matter of discussion. This debate, in force at the present time, is the result of the imbalance between the supply and organ demand of our society, which has increased the waiting list and has created a difficult ethical dilemma to solve. To ensure a good short term result is not enough, to obtain a result comparable to that with the de novo HT is almost impossible and the fact of accepting less optimal donors for these patients or the urgent indication for redo procedures in unstable patients had probably contributed to the worse results after the first CRT [4]. This has been a matter of study for multiple groups, where they tried to identify factors involved in the survival that would establish a unified criterion for the correct indication of CRT [5-14]. 
There have been studied factors related to the receptor (such as age, the reason for the CRT or some comorbidities), technical aspects such as the ischemic time or even the technique used, and characteristics of the donor [5-15], none of them guaranteeing long-term success. The experience gained in each centre, the specific protocol of each group and individual assessment are so far the only variables that appear to influence the outcome in the CRT.

The first CRT performed at the Clinica Universidad de Navarra was in 1991. Twenty years after, it remains controversial. The aim of this paper is to show our experience trying to identify parameters that will allow us achieve better results in the future.

\section{Material and Methods}

We reviewed all CRT performed at the Clinica Universidad de Navarra from 1984 to 2013. All patients followed the standard evaluation protocol for their inclusion on the waiting list, mainly related to severe disease or neoplasia and pulmonary hypertension.

Studied variables were: a) characteristics of the recipients, b) surgical aspects, c) donor data available and d) pathological biopsy results as well as coronary angiography and stress echocardiogram.

The monitoring of all patients was performed on our outpatient Cardiac Transplantation Unit consult. The protocol was biweekly during the first three months, fourth, sixth, ninth and twelfth month and every six months thereafter. At each visit general analysis (blood count, renal function, electrolytes, liver function tests and immunosuppressant levels) and transthoracic Doppler echocardiography alternating with stress echocardiography was requested.

During the early years, cardiac biopsies were performed monthly until the third month. Since five years ago, and annually, CT coronary angiography and dobutamine stress echocardiography for GVD study is performed, relegating invasive coronary angiography to those in which any of the above tests results positive.

Triple therapy with cyclosporine, azathioprine and prednisone was used until 1997 in relation to immunosuppression. Azathioprine has been replaced by mycophenolate mofetil. In the case of retransplanted patients our policy was to reinforce immunosuppression by substituting cyclosporine and tacrolimus using mTOR inhibitors in patients diagnosed with GVD.

Continuous variables are presented as mean and standard deviation and categorical variables as proportions. Operative mortality was defined as death that happened within the first thirty postoperative days or during hospitalization. Survival of the first and second graft of the RTC patients and according to its indication was compared too. Analysis was performed by Kaplan-Meier method and survival rate were compared using the log-rank test. A p-value lower than 0.05 was considered as statistically significant. All analyses were performed using SPSS statistical package for Microsoft V21.

\section{Results}

Of a total of 279 CT, 29 transplants were performed in 14 patients: 13 were first transplants (one case was excluded for being transplanted at another centre), 14 (5\%) CRT and two third transplants (0.7\%).

\section{First transplant}

Table 1 shows the general characteristics of the CRT patients in their first transplant. The most frequent indication for transplant was dilated cardiomyopathy (10 cases in total): five ischemic, three idiopathic, one familiar and another enolic. Ten patients (77\%) were in NYHA functional class III and three (23\%) in class IV. Eight patients (62\%) had severe ventricular dysfunction (mean ejection fraction $26 \pm 9$ ). The most common blood group was the "A" (seven patients, 58\%). Three patients (23\%) had history of previous cardiac surgery. Hemodynamic data from cardiac catheterization ruled out the presence of severe pulmonary hypertension (GTP average of $11 \pm 7 \mathrm{mmHg}$, PVR $3 \pm 2$ Wood units and CO $4 \pm 2 \mathrm{~L} / \mathrm{min}$ ). Donors were mostly males of $29 \pm 12$ years, who died mainly due to head injury (54\%). All were orthotopic transplants, using in all the biatrial classical technique. Two procedures (15\%) were performed urgently (one was under intraortic balloon counterpulsation (IABP)). The mean graft ischemic time was $168 \pm 56$ minutes. The median survival of the graft until the CRT was $95 \pm 78$ months, with a median of 88 months.

\section{Retransplantation (CRT)}

Indications for the 14 CRT were: GVD in 10 cases (71\%), PGF in two (14\%) and AR in two (14\%). The presence of pulmonary hypertension was ruled out by catheterization (TPG $8 \pm 5 \mathrm{mmHg}$, PVR of $2 \pm 1$ Wood units and CO $4 \pm 2$ ). All were orthotopic procedures, using the bicaval technique in $64 \%$ of patients. In one case a "cardio-renal" double transplantation was performed. Four (29\%) were urgent procedures (three with IABP and one with a left ventricular assist device). The mean ischemic time was $210 \pm 46$ minutes. Operative mortality was $14 \%$ (two patients) and late 36\% (five patients), with a group survival of $65 \pm 61$ months (median of 62 months). Causes of exitus and evolution of each retransplant are shown in Table 2.

Two of the 14 patients with CRT required a third transplant during follow-up. The first patient was a male who required a third implant after 6 days because PGF and died in the first 24 hours due to multiorgan failure. The second patient was a male who was diagnosed with dilated cardiomyopathy who required a second transplant due to GVD 155 months after the first, and a third for the same reason 108 months after the second. Currently he is in NYHA functional class I. 


\begin{tabular}{|c|c|c|c|}
\hline & Total of HT $n=279$ & First transplant $n=13^{\star *}$ & Retransplant $n=14$ \\
\hline \multicolumn{4}{|c|}{ Receptor } \\
\hline Age $x \pm s t$ & $54 \pm 13$ & $49 \pm 9$ & $54 \pm 9$ \\
\hline \multicolumn{4}{|c|}{ Sex $n(\%)$} \\
\hline Male & $243(87,1)$ & $10(76,9)$ & $10(71,4)$ \\
\hline Female & $36(12,9)$ & $3(23,1)$ & $4(28,6)$ \\
\hline $\mathrm{BMI} \mathrm{x} \pm \mathrm{st}$ & $25 \pm 4$ & $24,2 \pm 2,5$ & $24,3 \pm 3,1$ \\
\hline \multicolumn{4}{|c|}{ Blood group * n (\%) } \\
\hline 0 & $104(37,3)$ & $3(25)$ & $3(21,4)$ \\
\hline A & $141(50,5)$ & $7(58,3)$ & $8(57,1)$ \\
\hline B & $20(7,2)$ & $2(16,7)$ & $2(14,3)$ \\
\hline $\mathrm{AB}$ & $14(5,0)$ & 0 & 0 \\
\hline \multicolumn{4}{|c|}{ Hemodynamic parameters $\mathrm{x} \pm \mathrm{st}$} \\
\hline TPG & $10 \pm 6$ & $11 \pm 7$ & $8 \pm 5$ \\
\hline PVR & $4 \pm 2$ & $3 \pm 2$ & $4 \pm 2$ \\
\hline $\mathrm{CO}$ & $3 \pm 2$ & $5 \pm 2$ & $2 \pm 1$ \\
\hline \multicolumn{4}{|c|}{ Previous cardiac surgery n (\%) } \\
\hline No & $179(64,2)$ & $10(76,9)$ & 0 \\
\hline Yes & $100(35,8)$ & $3(23,1)$ & $13(100)$ \\
\hline \multicolumn{4}{|c|}{ Surgery } \\
\hline Ischemic time $\mathrm{x} \pm \mathrm{st}$ & $194 \pm 58$ & $168 \pm 56$ & $210 \pm 46$ \\
\hline \multicolumn{4}{|c|}{ Technique $\mathrm{n}(\%)$} \\
\hline Classic & $154(55,2)$ & $12(92,3)$ & $5(35,7)$ \\
\hline Bicava & $125(44,8)$ & $1(7,7)$ & $9(64,3)$ \\
\hline \multicolumn{4}{|c|}{ Code n (\%) } \\
\hline Elective & $229(82,2)$ & $11(84,6)$ & $10(71,4)$ \\
\hline Urgent & $50(17,8)$ & $2(15,4)$ & $4(28,6)$ \\
\hline \multicolumn{4}{|c|}{ Ventricular assist device $\mathrm{n}(\%)$} \\
\hline Yes & & $1(7,7)$ & $4(28,6)$ \\
\hline ECMO & $243(87,4)$ & 0 & 0 \\
\hline IABP & $22(7,9)$ & 1 & 3 \\
\hline LVAD & $6(2,0)$ & 0 & 1 \\
\hline No & $8(2,8)$ & $12(92,3)$ & $10(71,4)$ \\
\hline \multicolumn{4}{|c|}{ Donor } \\
\hline \multicolumn{4}{|c|}{$\mathrm{Sex}^{*} \mathrm{n}(\%)$} \\
\hline Male & $246(88,2)$ & $11(84,6)$ & $12(85,7)$ \\
\hline Female & $33(11,8)$ & $1(7,7)$ & $1(7,7)$ \\
\hline Age $x \pm s t$ & $32 \pm 13$ & $29 \pm 12$ & $35 \pm 16$ \\
\hline $\mathrm{BMI} x \pm \mathrm{st}$ & $24,8 \pm 3,1$ & $23,4 \pm 2,2$ & $24,3 \pm 2,2$ \\
\hline \multicolumn{4}{|c|}{ Blood group * $\mathrm{n}(\%)$} \\
\hline 0 & $134(48,0)$ & $6(46,1)$ & $3(21,4)$ \\
\hline A & $125(44,9)$ & $4(30,8)$ & $8(57,1)$ \\
\hline B & $15(5,5)$ & $2(15,4)$ & $2(14,3)$ \\
\hline $\mathrm{AB}$ & $5(1,6)$ & 0 & 0 \\
\hline \multicolumn{4}{|c|}{ Cause of death ${ }^{\star} n(\%)$} \\
\hline Road accident & $137(49,1)$ & $7(53,8)$ & $6(42,9)$ \\
\hline Traumatism & $32(11,5)$ & $1(7,7)$ & $1(7,1)$ \\
\hline
\end{tabular}




\begin{tabular}{|c|c|c|c|}
\hline & Total of HT $n=279$ & First transplant $n=13^{\star *}$ & Retransplant $n=14$ \\
\hline \multicolumn{4}{|c|}{ Donor } \\
\hline \multicolumn{4}{|c|}{ Cause of death ${ }^{*} \mathrm{n}(\%)$} \\
\hline Suicide & $6(2,2)$ & $1(7,7)$ & 0 \\
\hline Hemorragic CVA & $77(27,6)$ & $3(23,1)$ & $4(28,6)$ \\
\hline Ischemic CVA & $4(1,4)$ & 0 & $1(7,1)$ \\
\hline Cerebral anoxia & $11(3,9)$ & 0 & $1(7,1)$ \\
\hline Others & $12(4,6)$ & 0 & 0 \\
\hline \multicolumn{4}{|c|}{ Follow up } \\
\hline \multicolumn{4}{|c|}{ Survival (months) } \\
\hline $\mathrm{x} \pm \mathrm{st}$ & $142 \pm 8$ & $95 \pm 78$ & $65 \pm 61$ \\
\hline median & 125 & 88 & 62 \\
\hline
\end{tabular}

* Missed data

** A first transplant was excluded because of not being performed in our center

BMI: Body mass index $\left(\mathrm{kg} / \mathrm{m}^{2}\right)$; CO: Cardiac output; CVA: Cerebrovascular accident; ECMO: Extracorporeal membrane oxigenator; IABP: Intraaortic balloon pump; LVAD: Left ventricular assist device; TPG: Transpulmonary gradient; PVR:

Pulmonary vascular resistance

Table 1: General characteristics

\begin{tabular}{|c|c|c|c|c|c|c|c|}
\hline & Sex & Indication & RTC year & Exitus & Cause of exitus & RTC Sv & $3^{\text {rd }}$ trasplant \\
\hline 1 & Female & PGF & 1991 & Yes & PGF & 29 days & \\
\hline 2 & Male & GVD & 1992 & Yes & PGF & 6 days & Yes \\
\hline 3 & Male & PGF & 1993 & Yes & Multiorgan failure & 24 hours & \\
\hline 4 & Male & GVD & 1994 & Yes & Sudden death & 5 years and 70 days & \\
\hline 5 & Male & GVD & 1996 & No & & 16 years and 7 months & \\
\hline 6 & Female & GVD & 1998 & Yes & Cerebral lymphoma & 6 years and 49 days & \\
\hline 7 & Female & $\mathrm{AR}$ & 2000 & Yes & GVD & 363 days & \\
\hline 8 & Female & GVD & 2001 & No & & $\begin{array}{l}11 \text { years } 7 \text { months } \\
\text { and } 17 \text { days }\end{array}$ & \\
\hline 9 & Male & GVD & 2001 & Yes & Infecction & 4 years and 336 days & \\
\hline 10 & Male & GVD & 2003 & No & & 9 years and 4 months & Yes \\
\hline 11 & Male & GVD & 2005 & Yes & Accident & $\begin{array}{c}7 \text { years } 5 \text { months and } \\
20 \text { days }\end{array}$ & \\
\hline 12 & Male & GVD & 2006 & No & & 6 years and one day & \\
\hline 13 & Female & GVD & 2011 & No & & $\begin{array}{l}1 \text { year, } 6 \text { months and } \\
12 \text { days }\end{array}$ & \\
\hline 14 & Male & GVD & 2013 & No & & 28 days & \\
\hline
\end{tabular}

AR: Acute rejection; GVD: Graft vascular disease; PGF: Primary graft failure; CRT: Cardiac retransplantation; Sv: Survival

Table 2: Characteristics of each retransplant. Reason for retransplantation, year of performance and current status of each retransplanted patient

Figure 1 shows the survival curve of the first and second graft in CRT patients ( $p=0.851$ first graft median 87 vs 74 months for the second). Patients retransplanted because of PGF or AR had a significantly lower survival compared with those retransplanted due to GVD (PGF and AR survival mean 6 days vs 106 months GVD, p = 0.000) (Figure 2).

\section{Discussion}

CRT continues to be a matter of debate since the first one performed in 1968 [4]. The suboptimal results after the first procedures and the correct use of resources, needed at present, makes difficult to decide when to indicate a new transplant in patients with graft dysfunction. Our CRT rate is higher than the one published in the Spanish Registry [2], with a similar survival between the first and the second graft.

One of the most important questions to which all publications have wanted to answer is the identification of factors that could determine the outcome of these patients. After a retrospective analysis of 106 CRT in 42 centres, Radovancevic, et al. found that factors such as RA, FPI, female donor, ischemia time greater than 240 minutes and the need for a new procedure within the first six months, were factors that predicted a worse survival [5]. In our series we did not find such associations. Most of the patients undergoing the first transplant had no history of previous CEC and the increase in the ischemic time of RTC patients could be related to the geographic availability of the donor or a more laborious procedure duet to the adhesions of the first procedure, without apparently being a reason to prevent or contraindicate a redo transplant. Many other factors have been studied, like the period when the intervention was performed or the patient's hemodynamic stability. The acceptance of the bicaval technique as th- 
e technique of choice relegated the classic biatrial technique described by Lower and Shumway [16] into the background. This change can also be seen in our series, since most procedures were done by bicaval technique in the RTC. Regarding the hemodynamic stability, we have observed an increase in the procedures performed urgently (first transplant 1 vs CRT 4) and / or some type of ventricular assist (first transplant 1 vs CRT 4) according to what is described in the Spanish cardiac transplant registry [2]. It is understood that patients requiring the implantation of a ventricular assist device as bridge to transplant are in a worse hemodynamic condition, and would not present a higher cardiac mortality compared to other associated comorbidities [16]. It does not seem appropriate the concept that the fact of making an RTC should be an urgent urgent procedure. The cause of graft failure is probably the major determinant which could determine the prognosis of these patients. As has been reported in other studies [5-14], in our centre too, those retrasplanted because of AR and PGF presented a much lower survival when compared to that obtained in patients reoperated due to GVD. For this reason, since 1996 is our criterion not to retransplant AR or PGF patients, using in these mechanical devices for hemodynamic stabilization. Following this decision, the operative mortality was null in the CRT, being the GVF the most frequent and almost unique indication for the CRT.

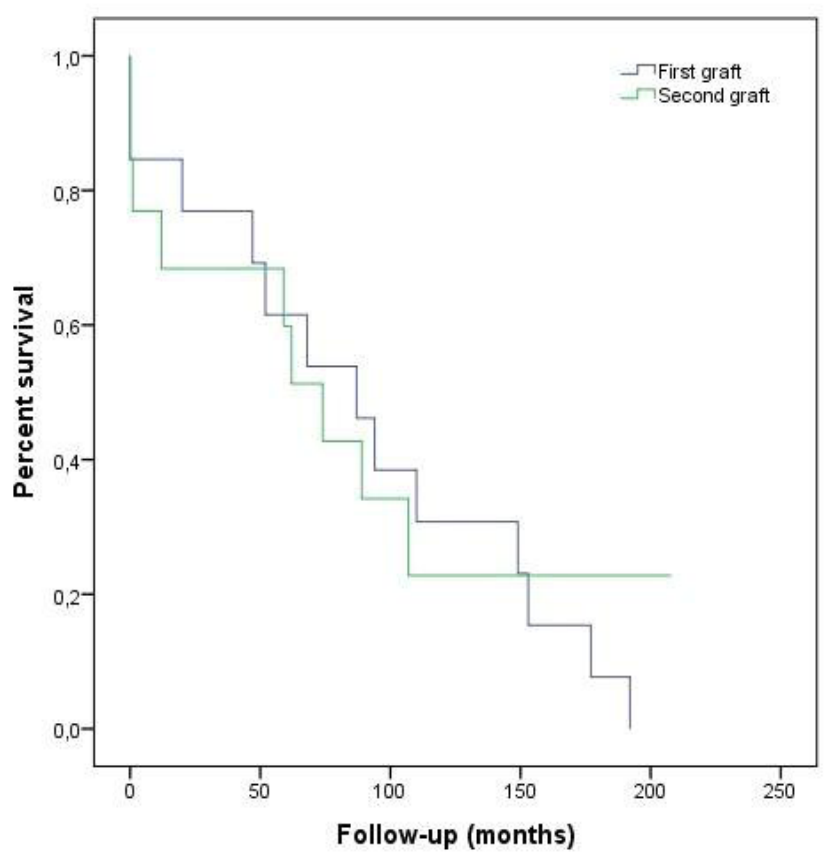

Figure 1: Survival curves of the first and second graft

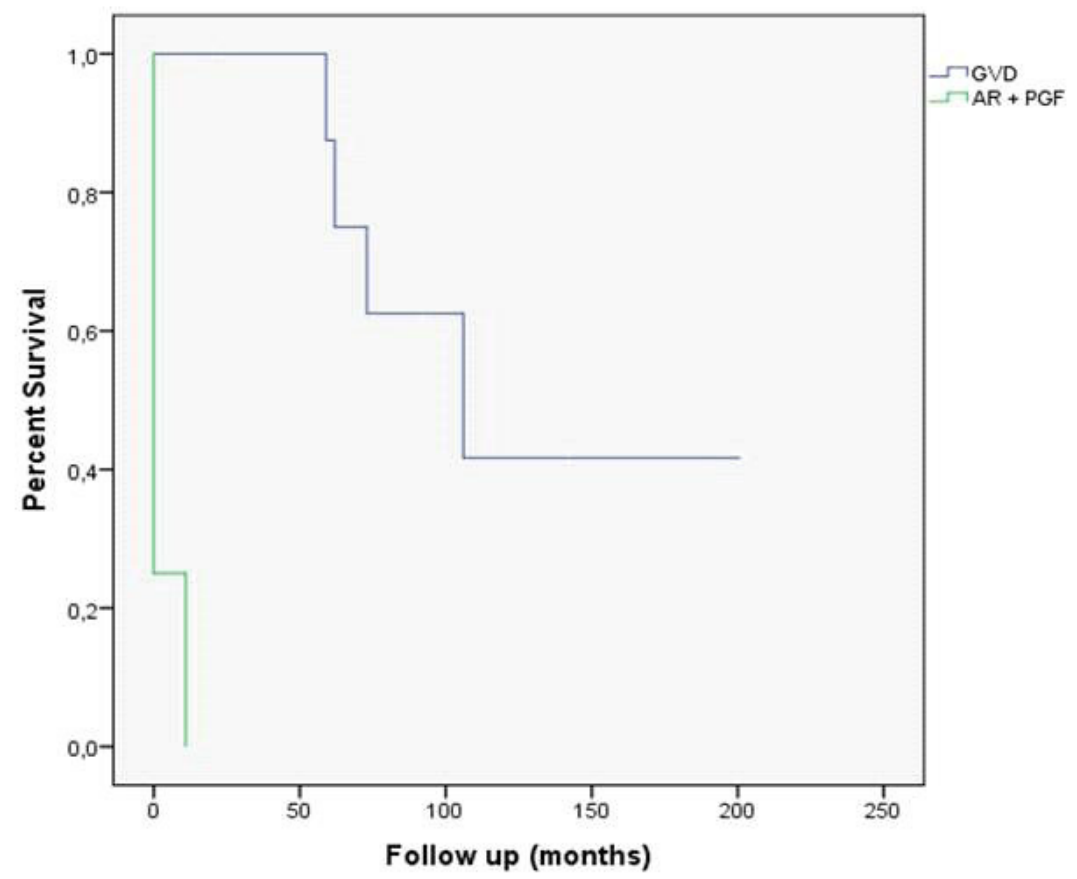

Figure 2: Survival curves compared according to the cause of graft dysfunction (AR + PGF vs. GVD) 
And while overall results have improved, complications still exist. During the first year the risk of developing AR is what most influences the prognosis, infections next and GVD or malignancy affects the long-term survival [2,3]. Our results reflect this mortality due to HT complications: three of the six patients who died did so within the first month (two because of PGF and one due to multiorgan failure) all of them before 1996 and the rest much later, secondary to infection, tumours, accident or sudden death. It is necessary to consider the relationship of these complications with the side effects of the chronic immunosuppressive therapy. We believe that the immunosuppressive treatment should be individualized according to the risk of each receptor and that it needs to be taken into account the importance of early detection of such complications. In our center, new imaging techniques of great sensitivity for GVD detection have relegated routinely cardiac catheterization to selected cases [19].

The selection, assessment and individualized optimization of the CRT candidate is the cornerstone to ensure a good result not only in short and long term. In the serie of Copeland, et al. [6], after analyzing 28 CRT (four third retransplants and a fourth retransplantation), they considered the CRT as a viable option in certain cases, supporting the concept of "multitransplant" for the future. We support this idea of individualized strict evaluation of each patient with CRT indication, following the same protocol and requirement than in the first one [6,7].

\section{Conclusion}

Based on our experience, cardiac retransplantation is a valid alternative in selected patients with severe graft dysfunction due to GVD. We believe that patients with AR and PGF should be handled with mechanical circulatory devices and once estabilized and if they meet the criteria, perform a CRT.

\section{Limitations}

The limitations of this study are those of retrospective studies. In one of the first transplant patients it was also not possible to collect all the data.

\section{Acknowledgements}

The authors wish to express their gratitude to Dr. Isabel Coma and Dr. Aida Suarez for their fruitful comments and advisory ideas.

\section{References}

1. Copeland JG, Griepp RB, Bieber CP, Billingham M, Scroeder JS, et al. (1977) Successful retransplantation of the human heart. J Thorac Cardiovasc Surg 73: 242-7. 2. González-Vilchez F, Gómez-Bueno M, Almenar L, Crespo-Leiro MG, Arizón JM, et al. (2014) Registro Español de Trasplante Cardiaco. XXV Informe Oficial de la Sección de Insuficiencia Cardiaca y Trasplante Cardiaco de la Sociedad Española de Cardiología (1984-2013). Rev Esp Cardiol 67: 1039-51.

3. Yusen RD, Christie JD, Edwards LB, Kucheryavaya AY, Benden C, et al. (2013) The Registry of the International Society for Heart and Lung Transplantation: Thirtieth Official Adult Heart Transplant Report-2013. J Heart Lung Transplant 32: 965-78.

4. Srivastava R, Keck BM, Bennett LE, Hosenpud JD (2000) The results of cardiac retransplantation: an analysis of the Joint International Society for Heart and Lung Transplantation/United Network for Organ Sharing Thoracic Registry. Transplantation 70: 606-12.

5. Belli E, Leoni Moreno JC, Hosenpud J, Rawal B, Landolfo K (2014) Preoperative risk factors predict survival following cardiac retransplantation: analysis of the United Network for Organ Sharing database. J Thorac Cardiovasc Surg 147: 1972-7.

6. Radovancevic B, McGiffin DC, Kobashigawa JA, Cintron GB, Mullen GM, et al. (2003) Retransplantation in 7,290 primary transplant patients: a 10-year multiinstitutional study. J Heart Lung Transplant 22: 862-8.

7. Copeland H, Coelho-Anderson R, Mineburg N, McCarthy M, Copeland JG (2011) Elective cardiac retransplantation: a viable option that can be repeated. J Thorac Cardiovasc Surg 141: 822-7.

8. Goerler H, Simon A, Gohrbandt B, Hagl C, Oppelt P, et al. (2008) Cardiac retransplantation: is it justified in times of critical donor organ shortage? Long-term single-center experience. Eur J Cardiothoracic surg 34: 1185-90.

9. Saito A, Novick RJ, Kiaii B, McKenzie FN, Quantz M, et al. (2013) Early and late outcomes after cardiac retransplantation. Canadian J Surgery 56: 21-6.

10. Topkara VK, Dang NC, John R, Cheema FH, Barbato R, et al. (2005) A decade experience of cardiac retransplantation in adult recipients. J Heart Lung Transplant 24: 1745-50.

11. Atluri P, Hiesinger W, Gorman RC, Pochettino A, Jessup M, et al. (2008) Cardiac retransplantation is an efficacious therapy for primary cardiac allograft failure. J Cardiothoracic surg 3: 26-31.

12. John R, Chen JM, Weinberg A, Oz MC, Mancini D, et al. (1999) Long-term survival after cardiac retransplantation: a twenty-year single-center experience. J Thoracic cardiovasc surg 117: 543-55.

13. Tsao L, Uriel N, Leitz K, Naka Y, Mancini D (2009) Higher rate of comorbidities after cardiac retransplantation contributes to decreased survival. J Heart Lung Transplant 28: 1072-4.

14. Johnson MR, Aaronson KD, Canter CE, Kirklin JK, Mancini DM, et al. (2007) Heart retransplantation. American Journal if Transplantation 7: $2075-81$.

15. Vistarini N, Pellegrini C, Aiello M, Alloni A, Monterosso C, et al. (2010) Should we perform heart retransplantation in early graft failure? Transpl Int 23: 47-53. 16. Lower RR, Stofer RC, Shumway NE (1961) Homovital transplantation of the heart. J Thorac Cardiovasc Surg 41: 196-204.

17. Peura J, Colvin-Adams M, Francis GS, Grady KL, Hoffman TM, et al. (2012) Recommendations for the use of mechanical circulatory support: device strategies and patient selection: a scientific statement from the American Heart Association. Circulation 126: 2648-67.

18. Khan MS, Mery CM, Zafar F, Adachi I, Heinle JS, et al. (2012) Is mechanically bridging patients with a failing cardiac graft to retransplantation an effective therapy? Analysis of the United Network of Organ Sharing database. J Heart Lung Transplant 31: 1192-8.

19. Pollack A, Nazif T, Mancini D, Weisz G (2013) Detection and imaging of cardiac allograft vasculopathy. JACC Cardiovasc Imaging 6: 613-23. 


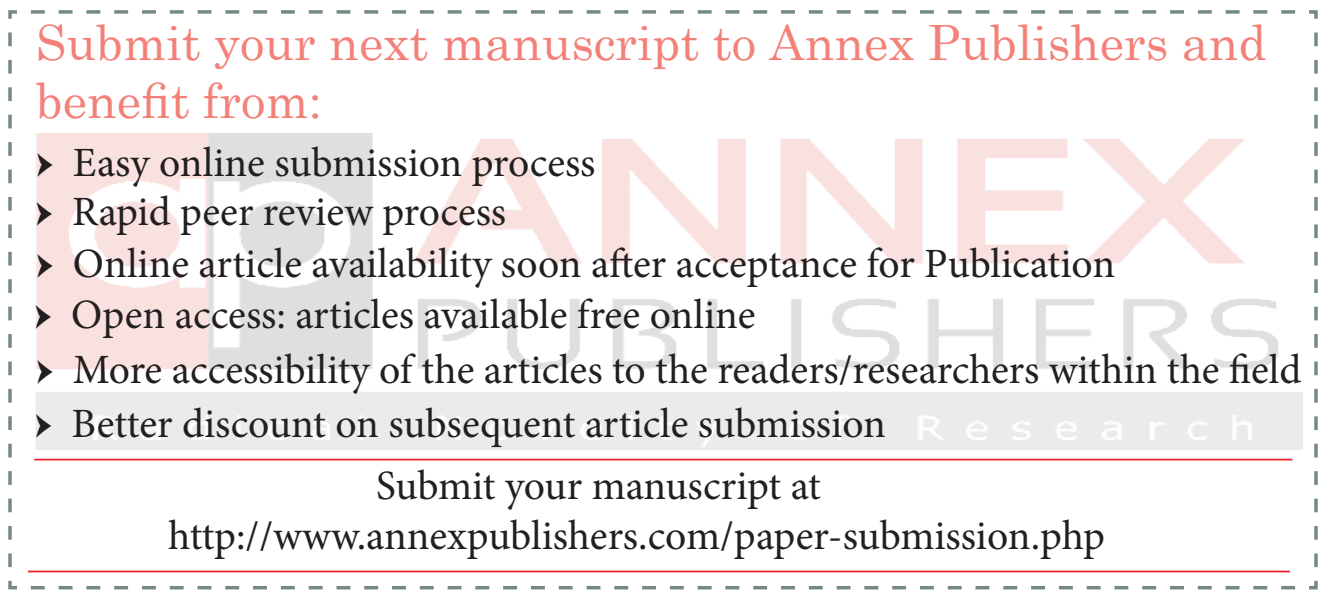

